\title{
Performance of bidimensional location quotients for constructing input-output tables
}

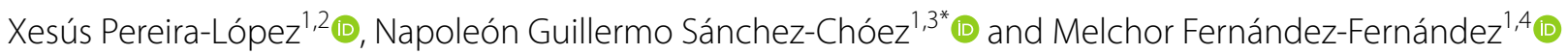

\section{${ }^{*}$ Correspondence:}

napoleon.sanchez@epn.

edu.ec

${ }^{3}$ Departamento de Estudios

Organizacionales y Desarrollo

Humano, Escuela Politécnica

Nacional, Avda. Ladrón

de Guevara, E11-253, P.O.

Box 17-01-2759, Quito,

Ecuador

Full list of author information is available at the end of the article

\begin{abstract}
This article seeks to verify the extent to which the formulation of two-dimensional location quotients (2D-LQ) entails a methodological advance in building or generating economic accounts related to sub-territories drawing from basic information. The inputoutput tables of the Euro Area 19 for 2010 and 2015 are references for analysis. We have used five statistics to measure similarity between true domestic coefficient matrices for ten countries (Austria, Belgium, Estonia, France, Germany, Italy, Latvia, Slovakia, Slovenia, and Spain) and the matrices they generate using nonsurvey techniques (CILQ, FLQ, $A F L Q$, and 2D-LQ). The focus substantially centers on ranking methodological efficiency by comparing the results of the four techniques mentioned above. The scope of the work employs standard parameters (associated with 2D-LQ) as guidance to ascertain the optimum parameters.
\end{abstract}

Keywords: Location quotients, FLQ, 2D-LQ, Non-survey method, Regional inputoutput tables

JEL Classification: C13, C67, R19

\section{Introduction}

Input-output (IO) analysis is common to economics. There are many useful associated multisectoral models to quantify impacts (economic, environmental, etc.) in territories with IO survey frameworks, usually regions, countries, and supranational unions. Yet its applicability becomes complicated when implemented at a sub-territorial level, particularly smaller regions and areas (e.g., counties), which have no accounting frameworks for elevated costs and even lack basic information to execute robust projects. Even so, nonsurvey techniques remain in use to generate sub-territorial tables based on the analytical capacity of the characteristic IO sector breakdown.

In general, economic accounts available for a given territory will serve as a reference. The available sub-territorial data (resulting from disaggregation) refer to certain basic magnitudes (industry production, employment, or gross added value) and match the same year with the corresponding sectoral breakdown. Data from a higher territorial level are thus commonly used to generate an IO table at local, regional and even national levels. Though different methods exist (Morrison and Smith 1974; Schaffer and Chu 1969; Bonfiglio and Chelli 2008), Location Quotients (LQs) are the most widely used methods, especially Flegg's

(c) The Author(s) 2021. This article is licensed under a Creative Commons Attribution 4.0 International License, which permits use, sharing, adaptation, distribution and reproduction in any medium or format, as long as you give appropriate credit to the original author(s) and the source, provide a link to the Creative Commons licence, and indicate if changes were made. The images or other third party material in this article are included in the article's Creative Commons licence, unless indicated otherwise in a credit line to the material. If material is not included in the article's Creative Commons licence and your intended use is not permitted by statutory regulation or exceeds the permitted use, you will need to obtain permission directly from the copyright holder. To view a copy of this licence, visit http://creativeco mmons.org/licenses/by/4.0/. 
Location Quotient (FLQ) or a modified version thereof, i.e., augmented FLQ (AFLQ). Different studies have held that LQs constitute an advance in generating IO tables (Flegg and Webber 1997, 2000; Flegg et al. 1995). Therefore, it is essential to select the LQ version to use, either alone or supplemented by adjustment techniques (Lamonica et al. 2020). Though there is no clear majority on which LQ version yields the best results, some studies (Bonfiglio and Chelli 2008; Jahn et al. 2020) show the prevalence of FLQ and AFLQ, while others (Zhao and Choi 2015; Lamonica and Chelli 2018) take an opposing view to favor other ratios.

FLQ and AFLQ techniques have a parameter associated with the size of a certain magnitude of the sub-territory that should be delimited within an interval. The optimum parameter per se varies from one sub-territory to another, though multiple research papers undertake this quest for the optimum value (Kowalewksi 2015; Flegg and Tohmo 2016; Lamonica and Chelli 2018). This unknown value becomes problematic, as its calculation is thus arduous (Lampiris et al. 2019), probably because it is relatively sensitive due to the design of the corresponding formulas. Recently and in a context of identical available information, Pereira-López et al. (2020) rendered a two-dimensional reformulation of LQs (for domestic flow tables, though extrapolated to total flows with certain nuances), thus employing two parameters. However, these parameters are not associated with the size of the sub-territories but rather with the degree of specialization of the various branches of activity and sector size (by rows and columns, respectively). Their sensitivity will thus differ for FLQ and AFLQ parameters.

In short, the process of generating sub-territorial IO tables has not yet been clearly defined. Researchers are avidly searching for the most suitable LQ and parameters capable of yielding robust results. This paper mainly seeks to look at LQ performance and, in particular, uncover the most effective way to ascertain the standard parameters used in their formulation, especially regarding 2D-LQ. The present introduction (Sect. 1) is followed by an LQ overview (methods) in Sect. 2. Section 3 describes the data used and Sect. 4 (results) contains an analysis of traditional LQs and the 2D-LQ method. Finally, Sect. 5 compares the four examined LQs, identifies guiding parameters for 2D-LQ and indicates the main conclusions drawn.

\section{Methods}

This section is a brief description of the main LQs. Numerous studies contain further details, including Schaffer and Chu (1969), Morrison and Smith (1974), Round (1978), Flegg and Webber (1997, 2000), Miller and Blair (2009), and Pereira-López et al. (2020).

The Simple Location Quotient (SLQ) is the most common approach, which compares the relative weight of a certain sectoral magnitude of a sub-territory with its relative weight in the territory. Analytically,

$$
\mathrm{SLQ}_{i}=\frac{x_{i}^{R} / x^{R}}{x_{i}^{N} / x^{N}}=\frac{x_{i}^{R} / x_{i}^{N}}{x^{R} / x^{N}}=\frac{w x_{i}^{R}}{w x^{R}},
$$

where $x_{i}^{R}$ is production (for instance) of sector $i$ in region $R, x^{R}$ is the production in region $R, x_{i}^{N}$ is the production of sector $i$ in the entire country $(N)$, and $x^{N}$ is the production of the entire country. Therefore, $w x_{i}^{R}$ represents the weight of the production 
of region $R$ 's sector $i$ in the production of the total economy's sector $i$; and $w x^{R}$ corresponds to the participation of the production of region $R$ in the total production of the country. This LQ in some way indicates whether the sector can be self-sufficient or an exporter, or whether the sector imports from other regions. However, it does not consider the importance of the purchaser section.

The Cross-Industry Location Quotient (CILQ) considers the relative importance of the selling industry to the purchasing industry, as shown below:

$$
\mathrm{CILQ}_{i j}=\frac{\mathrm{SLQ}_{i}}{\mathrm{SLQ}_{j}}=\frac{w x_{i}^{R}}{w x_{j}^{R}},
$$

where the subscript $j$ refers to purchasing sectors.

Given that the formulation above excludes, for the sake of simplification, the size of the region in the process, Flegg and Webber (1997) proposed the FLQ method, which is defined as follows:

$$
\mathrm{FLQ}_{i j}=\mathrm{CILQ}_{i j} \cdot\left[\log _{2}\left(1+\frac{x^{R}}{x^{N}}\right)\right]^{\delta}, 0<\delta<1 .
$$

The effect of region size is usually abbreviated as:

$$
\lambda=\left[\log _{2}\left(1+\frac{x^{R}}{x^{N}}\right)\right]^{\delta} .
$$

In this expression, the parameter $\delta$ is a coefficient associated with interregional imports, after which $\lambda$ works as a corrective element of the CILQ. Following the standard procedure, the regional technical coefficients $a_{i j}^{R}$ are the result of corrections on the national coefficients $a_{i j}^{N}$, namely:

$$
\begin{aligned}
& a_{i j}^{R}=a_{i j}^{N} \cdot \mathrm{FLQ}_{i j} \quad \text { if } \mathrm{FLQ}_{i j} \leq 1 \\
& a_{i j}^{R}=a_{i j}^{N} \quad \text { if } \mathrm{FLQ}_{i j}>1 .
\end{aligned}
$$

McCann and Dewhurst (1998) warned that FLQ does not appropriately address scenarios in which regional industries are more specialized than national industries. Flegg and Webber (2000) then rectified columns (semi-logarithmic smoothing) for specialized purchasing sectors. The result was the Augmented FLQ (AFLQ):

$$
\mathrm{AFLQ}_{i j}=\left\{\begin{array}{l}
\mathrm{FLQ}_{i j} \cdot \log _{2}\left(1+\mathrm{SLQ}_{j}\right) \quad \text { if } \mathrm{SLQ}_{j}>1 \\
\mathrm{FLQ}_{i j} \quad \text { if } \mathrm{SLQ}_{j} \leq 1
\end{array} .\right.
$$

Thus, greater sectoral specialization leads to a larger coefficient and consequent reduction in imports.

As an initial step in designing a generalization of the Flegg methodology, PereiraLópez et al. (2020) proposed a bidimensional approach (2D-LQ) to estimate domestic coefficients at the sub-territorial level. This technique can be extrapolated to other contexts, such as generating flow matrices, total coefficients, or multipliers.

This bidimensional approach is represented in the following matrix expression: 


$$
\tilde{A}^{R}=R(\alpha) A^{N} S(\beta)
$$

where $A$ is a matrix of intermediate domestic coefficients, $R(\alpha)$ and $S(\beta)$ are diagonal matrices, whose elements appear in the main diagonal work as weighting factors. Scalars $\alpha$ and $\beta$ are the influential parameters in row and column corrections, respectively. There are different ways to address these corrections, and they do not necessarily have the same behavior. The authors indicate the possibility of using different smoothing (semilogarithmic, potential, or hyperbolic tangent function) to address such corrections.

The generic element of the projected matrix, $\tilde{A}^{R}$, through the proposed alternative, is:

$$
\tilde{a}_{i j}^{R}=\left\{\begin{array}{l}
\left(\mathrm{SLQ}_{i}\right)^{\alpha} a_{i j}^{N}\left(w x_{j}^{R}\right)^{\beta} \quad \text { if } \mathrm{SLQ}_{i} \leq 1 \\
{\left[\frac{1}{2} \tan h\left(\mathrm{SLQ}_{i}-1\right)+1\right]^{\alpha} a_{i j}^{N}\left(w x_{j}^{R}\right)^{\beta} \quad \text { if } \mathrm{SLQ}_{i}>1}
\end{array} .\right.
$$

The function $y=\tan h(x)$ is propitious, since it is increasing for $x>0$, and when $x$ tends to $+\infty$, the function approaches 1 , expressing an asymptotic behavior with respect to line $y=1$. In this context, the function $\left[\frac{1}{2} \tan h\left(\mathrm{SLQ}_{i}-1\right)+1\right]^{\alpha}$ permits slightly higher factors (when $\mathrm{SLQ}_{i}>1$ ) than the ones in the reference table.

\section{Data sources}

Contrasting estimated coefficients against true coefficients is no easy task for certain regions or small areas, given the insufficiency of data gleaned in surveys and even the non-uniformity of the information at different territorial levels, e.g., countries/regions. In this case, we opted to compare and contrast ten (10) Euro Area 19 countries (EA-19). The database downloaded from Eurostat (https://ec.europa.eu/eurostat/web/esa-supply-use-input-tables/data/database) contains symmetric $64 \times 64$ matrices at basic prices (product by product) [naio_10_cp1700]. IO tables (2010 and 2015) were then filtered for ten countries, namely Austria, Belgium, Estonia, France, Germany, Italy, Latvia, Slovakia, Slovenia, and Spain. For these purposes, it should be noted that these 10 countries represented $84.39 \%$ of EA-19 production (Austria 3.06\%, Belgium 4.22\%, Estonia $0.17 \%$, France $19.89 \%$, Germany $26.79 \%$, Italy $17.42 \%$, Latvia $0.21 \%$, Slovakia $0.85 \%$, Slovenia $0.39 \%$ and Spain $11.40 \%$ ). Their production volume was $83.79 \%$ in 2015: (Austria 3.27\%, Belgium 4.33\%, Estonia 0.21\%, France $19.79 \%$, Germany $28.27 \%$, Italy $15.99 \%$, Latvia 0.24\%, Slovakia $0.96 \%$, Slovenia $0.38 \%$ and Spain 10.35\%). Ireland, Malta, Portugal, Finland, Greece, Lithuania, Netherlands, Cyprus, and Luxembourg lacked IO tables for one or two years analyzed, or showed confidential or provisional data. For these reasons, the present analysis excluded the remaining nine countries.

The aforementioned extraction is based on the European System of Accounts (ESA) 2010, specifically on the Classification of Products by Activity (CPA) 2008. We opted to use sector outputs instead of the employment vector or gross added value, since, according to Flegg and Tohmo (2019), "It should be noted that the SLQ and CILQ are defined in terms of output rather than the more usual employment. Using output is preferable to using a proxy such as employment because output figures are not distorted by differences in productivity across regions." 


\section{Results}

\subsection{Analysis}

We used the following statistics to compare estimated domestic coefficient matrices (CILQ, FLQ, AFLQ and 2D-LQ) with true matrices to ascertain the most appropriate LQ approach for executing projections of sub-territorial IO tables. As an example, see the projection using LQs for Austria in 2010 (Additional file 1). These statistics are Standardized Total Percentage Error (STPE), Mean Absolute Difference (MAD), Mean Absolute Percentage Error (MAPE), Standard Deviation of the Mean Absolute Difference (SD-MAD), and Theil Index $(U)$. The following equations are used to calculate these statistics:

$$
\begin{aligned}
& \mathrm{STPE}=100 \sum_{i=1}^{n} \sum_{j=1}^{n}\left|\tilde{a}_{i j}^{R}-a_{i j}^{R}\right| / \sum_{i=1}^{n} \sum_{j=1}^{n} a_{i j}^{R}, \\
& \mathrm{MAD}=\frac{1}{n^{2}} \sum_{i=1}^{n} \sum_{j=1}^{n}\left|\tilde{a}_{i j}^{R}-a_{i j}^{R}\right|, \\
& \mathrm{MAPE}=\frac{100}{n^{2}} \sum_{i=1}^{n} \sum_{j=1}^{n}\left|\tilde{a}_{i j}^{R}-a_{i j}^{R}\right| / \sum_{i=1}^{n} \sum_{j=1}^{n} a_{i j}^{R}, \\
& \mathrm{SD}-\mathrm{MAD}=\sqrt{\frac{1}{n^{2}} \sum_{i=1}^{n} \sum_{j=1}^{n}\left(\left|\tilde{a}_{i j}^{R}-a_{i j}^{R}\right|-\mathrm{MAD}^{2}\right.}, \\
& U=100 \sqrt{\sum_{i=1}^{n} \sum_{j=1}^{n}\left(a_{i j}^{R}-\tilde{a}_{i j}^{R}\right)^{2} / \sum_{i=1}^{n} \sum_{j=1}^{n}\left(a_{i j}^{R}\right)^{2},}
\end{aligned}
$$

where $a_{i j}^{R}$ is the true sub-territorial coefficient-usually regional-and $\tilde{a}_{i j}^{R}$ is the estimated sub-territorial coefficient; $n$ is the number of products/sectors.

STPE is used to calculate the relative distance in absolute terms between the estimated coefficient and the true coefficient. Multiplying it by one hundred yields error as a percentage (Jalili 2000; Jackson and Murray 2004; Bonfiglio 2005; Flegg et al. 2016; Lampiris et al. 2019). MAD calculates the difference (in absolute values) between estimated and true coefficients, yielding the absolute mean of the differences when divided by the total number of elements in the matrix (Morrison and Smith 1974; Jackson and Murray 2004; Bonfiglio 2005; Bonfiglio and Chelli 2008; Miller and Blair 2009; Kowalewksi 2015; Wiebe and Lenzen 2016; Lamonica and Chelli 2018; Lampiris et al. 2019; Lamonica et al. 2020). MAPE is practically the average of STPE (Oosterhaven et al. 2003; Mínguez et al. 2009; Miller and Blair 2009; Lampiris et al. 2019; Flegg and Tohmo 2019; Jahn et al. 2020). SD-MAD is the standard deviation to the median absolute deviation between the estimated and true coefficients (Lamonica and Chelli 2018). Theil Index is known as the inequality index, since it estimates the overall distance ratio, and thus indicates perfect equality when equal to zero (Jalili 2000; Lahr and Stevens 2002; Jackson and Murray 
2004; Bonfiglio 2005; Flegg and Tohmo 2013, 2019; Kowalewksi 2015; Flegg et al. 2016; Lampiris et al. 2019; Jahn et al. 2020). This study compares matrices element by element, unlike other works, which focus solely on sums by rows or columns through a matrix of coefficients or the Leontief inverse matrix. Working with sum vectors (rows or columns) yields inaccuracies, since errors are easily offset.

\subsection{Sensitivity analysis of traditional location quotients}

The starting point begins with sub-territorial coefficients generated by CILQ, FLQ, and AFLQ. As we have seen from (3) to (6), the last two equations incorporate the parameter $\delta$ (as an exponent), which is somehow associated with interregional imports. There have been numerous discussions regarding the optimal value for this parameter, though it should vary based on sub-territory size, since, in reality, the goal is to ascertain a suitable $\lambda$ that depends on $\delta$. For instance, Flegg and Webber (2000) suggest, in the absence of information, assigning 0.3 as the value for $\delta$. However, in a study for the Italian Le Marche region through the Monte Carlo simulation, Bonfiglio (2009) maintains that this parameter is centered on 0.3 (for FLQ) with an associated probability of $33 \%$ (with the interval width set at 0.1 ), and between 0.3 and 0.4 for AFLQ, with a probability of $38 \%$. In a study for 20 regions in Finland, Flegg and Thomo (2013) set this figure between 0.15 and 0.35. The results concur with the Bonfiglio study in that an optimal value of 0.3 can only be expected in a third of the regions, and thus a true optimal value has yet to be found. Kowalewksi (2015) applied an extension of the Flegg methodology and revealed values between 0.11 and 0.17 , which are relatively low compared to previous studies. Lampiris et al. (2019) compared technical coefficient matrices and estimated Leontief inverse matrices using traditional LQs for several EU countries. Their results allow us to affirm that AFLQ and FLQ yield better results for $\delta$ values between 0.1 and 0.3 , yet prove unsatisfactory for values higher than 0.3 .

Figures 1 and 2 show the STPEs related to traditional LQs for the ten countries studied (2010 and 2015). ${ }^{1}$ Both figures show that FLQ and AFLQ curves are convex around the optimum, yet exceed the (constant) value of CILQ considerably from certain thresholds marked by values of $\delta$. However, when $\delta$ tends to 1 , the curves behave nearly asymptotic (horizontal) and virtually converge. Once breaching thresholds, these two techniques must be ruled out to the detriment of the CILQ equation, even though the latter is much more elemental. As a general guideline, one can conclude that $\delta$ is quite sensitive when it tends to 1 on the left (values between 0 and 1 ). The statistical figures would also shoot off if selecting the wrong value, rendering the results questionable.

However, the substantial is clearly given by the degree of approximation of the different matrices. Therefore, larger countries seemingly behave better than smaller ones, which should not be surprising given that the higher their proportion, the more productive structures will resemble the reference area. The STPEs for France, Germany, Italy, and Spain (2010 and 2015) are lower than the figures for the other six countries analyzed. These results concur with the figures indicated for 2005 in Pereira-López et al. (2020). There is a similar diagnosis concerning the other four statistics. Refer to Appendix.

1 The charts are all associated with the STPE statistic. The results of the remaining statistics (MAD, MAPE, SD-MAD and Theil) are specified in Table 1 in Appendix. 


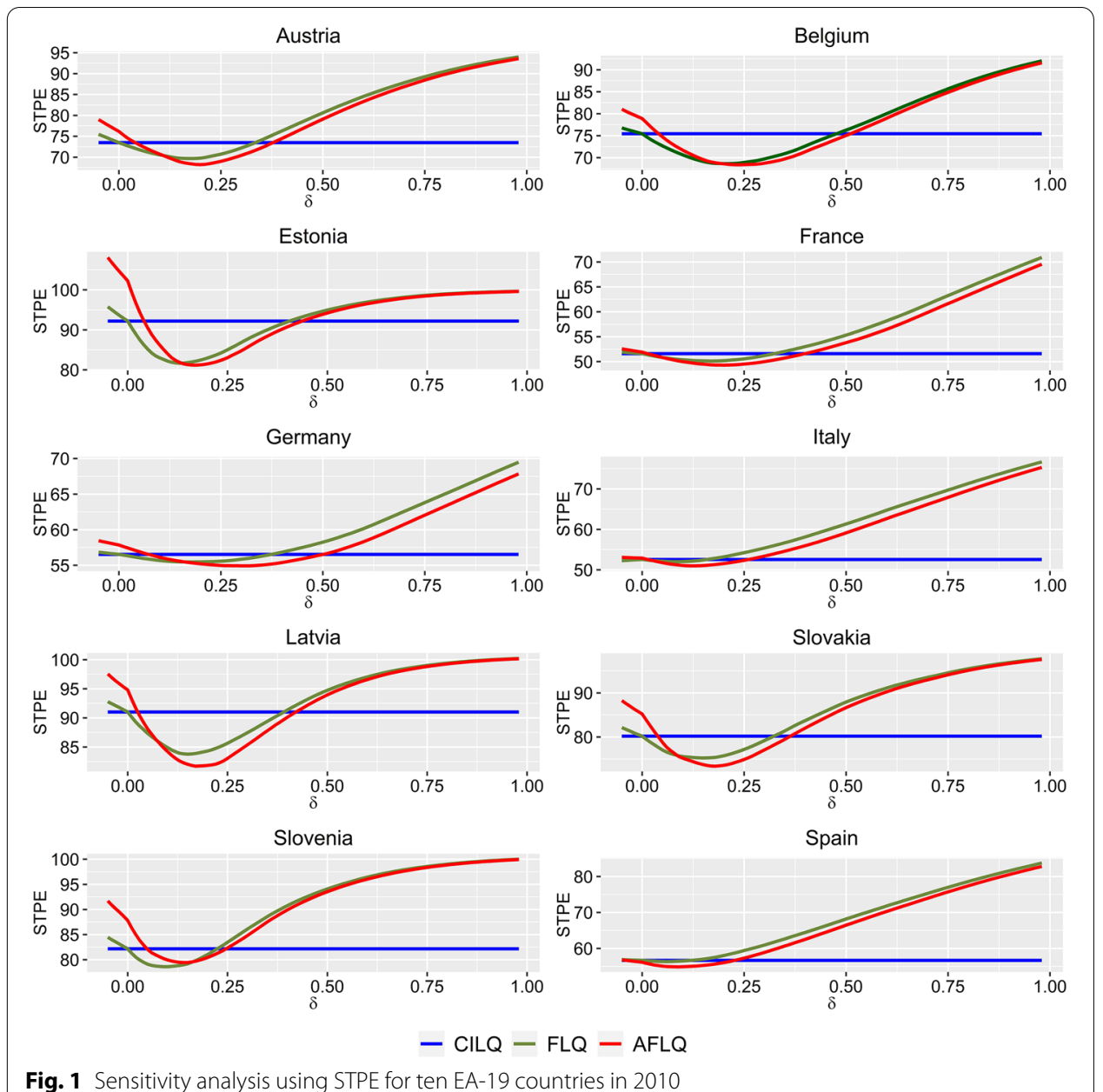

Though the mentioned figures appear rather explicit, certain $\delta$ parameters of the two examined curves intersect the CILQ line (not depending on $\delta$ ). Thus, out of the ten countries analyzed in 2010, only Belgium lets us assign the maximum value to the parameters for FLQ, which must be less than or equal to 0.47, and for AFLQ, which must be less than or equal to 0.5. France, Germany, Italy, and Spain yielded smaller relative distances between CILQ and the optimum associated with AFLQ, improving results by $4.46 \%, 2.86 \%, 8.23 \%$, and $3.20 \%$, respectively. Meanwhile, the other countries show greater distances, as clearly seen in Fig. 1. Nearly the same curves and corresponding intersections with the CILQ line reappear for 2015. For instance, the following extreme values: 0.52 in Belgium (for FLQ) and 0.57 in Germany (for AFLQ). France, Germany, Italy, and Spain yielded smaller relative distances between CILQ and the optimum for AFLQ (figures relatively similar to 2010 figures, namely 5.15\%, 3.91\%, 3.93\%, and 3.51\%, respectively). Once again, the other countries mark wider distances, though there is also more room for improvement since the STPEs are higher.

Compared to FLQ, AFLQ slightly reduces errors in matrix estimates. This circumstance repeats for virtually all the countries in 2010 and 2015. Slovenia (2010 and 2015) and Estonia (2015) are the sole exceptions, where positions are exchanged between both techniques. We thus would tend to work with AFLQ as the most efficient traditional 


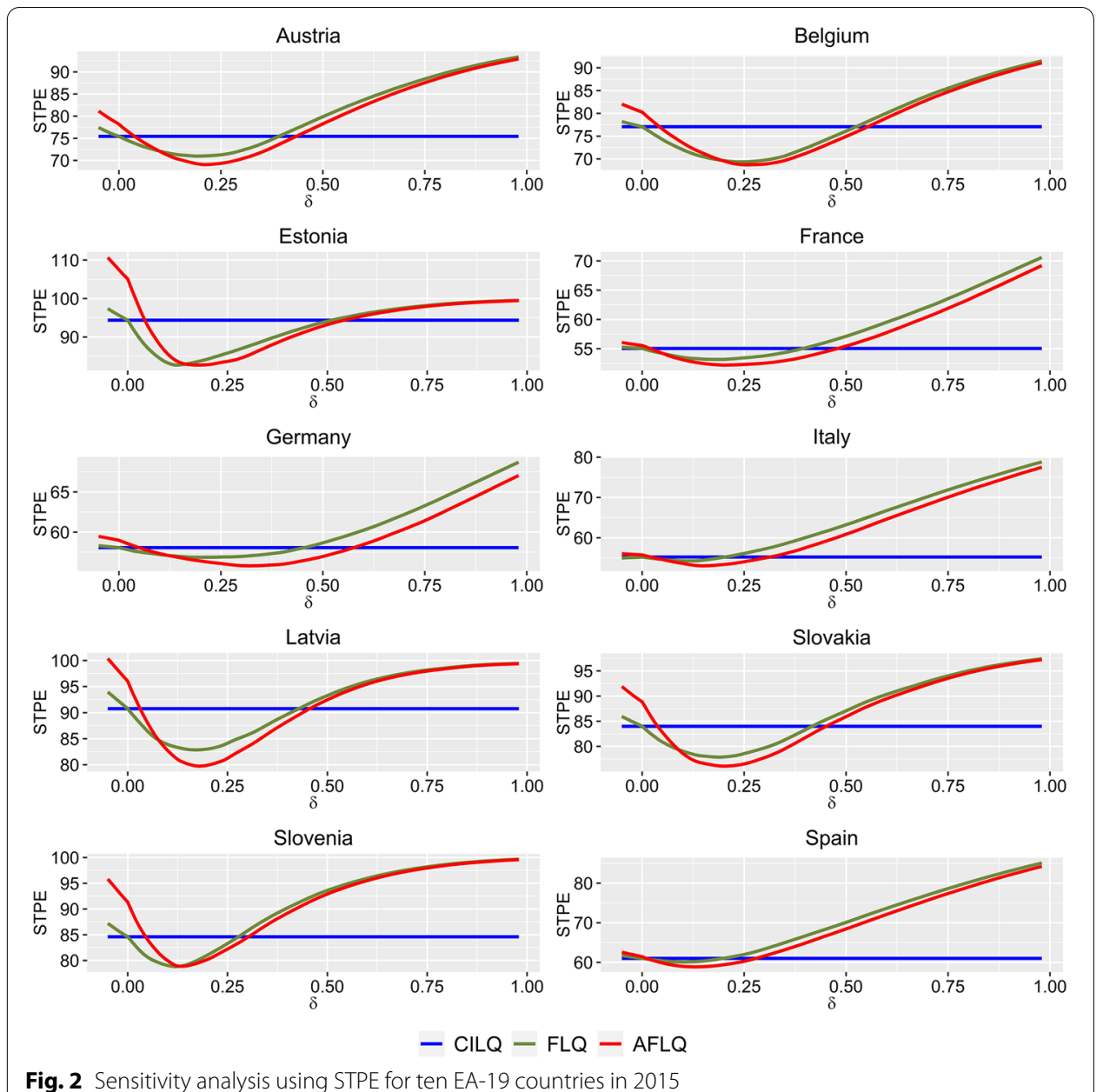

technique, albeit aware of the need to ascertain an optimal $\delta$, conditioned by the size of the sub-territories. In light of the figures above, when the value of $\delta$ exceeds 0.3, FLQ and AFLQ are no longer effective techniques, and CILQ thus becomes preferred to forestall estimation errors. One may surmise that the Flegg equation incorporates basic information (overall size of sub-territory), specifically in estimating, and alternatives could be sought to efficiently address this information and thus avoid the highly sensitive $\delta$, particularly from a given value (as indicated above). The foregoing becomes key in $2 \mathrm{D}-\mathrm{LQ}$ design, construed as one of the possible generalizations of Flegg's formula.

\subsection{Estimating parameters of the 2D-LQ method}

The 2D-LQ method is characterized by its use of the sectoral degrees of specialization at the sub-territorial level (by rows), yet with an alternative formulation that excludes the sub-territorial effect size at the global level. In other words, it seeks to circumvent the sensitivity of parameter $\delta$. This section graphically demonstrates the method's robustness and also indicates pairs of suitable parameters to apply in future LQ applications. Appendix contains the values of the global minimum statistics and associated pairs.

Figures 3 and 4 show three-dimensional, country-by-country representations of the STPE statistic against parameters $\alpha$ and $\beta$ for 2010 and 2015. The corresponding contour 

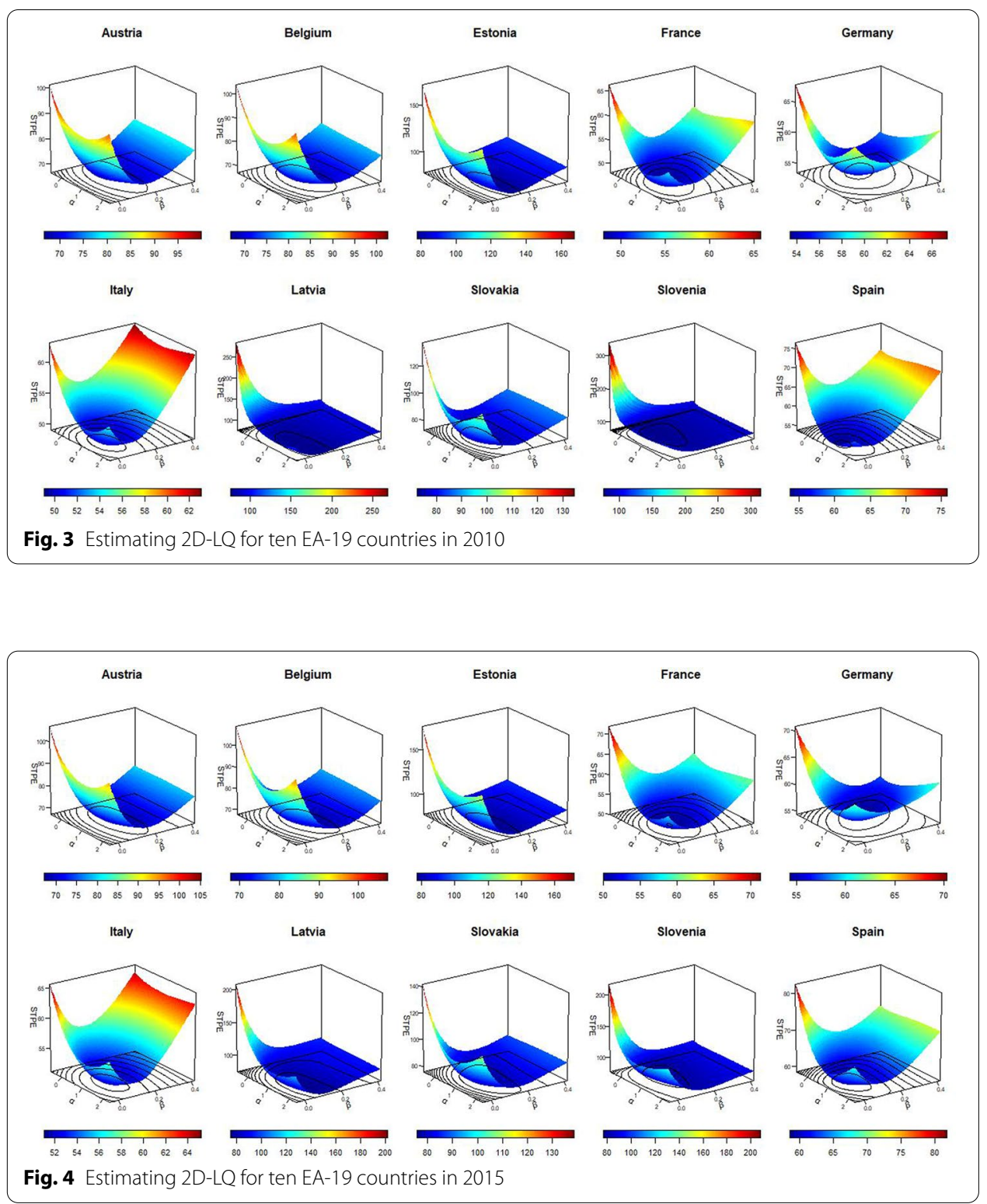

lines are also highlighted with a fixed gradation by country and year. The optimal pair of parameters and behavior of the scalar field in its environment is visible. Appendix contains information on the global minimums on each scalar field for STPE and the other four statistics. The scalar fields have a convex behavior.

The graphical representations for MAD and MAPE are identical and virtually similar for SD-MAD and U, though the statistics change when relativizing distances in another way. In the scalar fields, common patterns are not clear according to the size of the countries. Of course, there is a nearly perfect country-by-country match in the fields for the 2 years studied.

Movements through $\beta$ ( $y$ axis) entail more significant errors than movements through $\alpha$ ( $x$ axis). In general, the minimums tend to stay between 0.26 and 1.52 for $\alpha$ and 0.02 and 0.21 for $\beta$ (in 2010). The ranges in 2015 are quite similar, respectively, between 0.32 


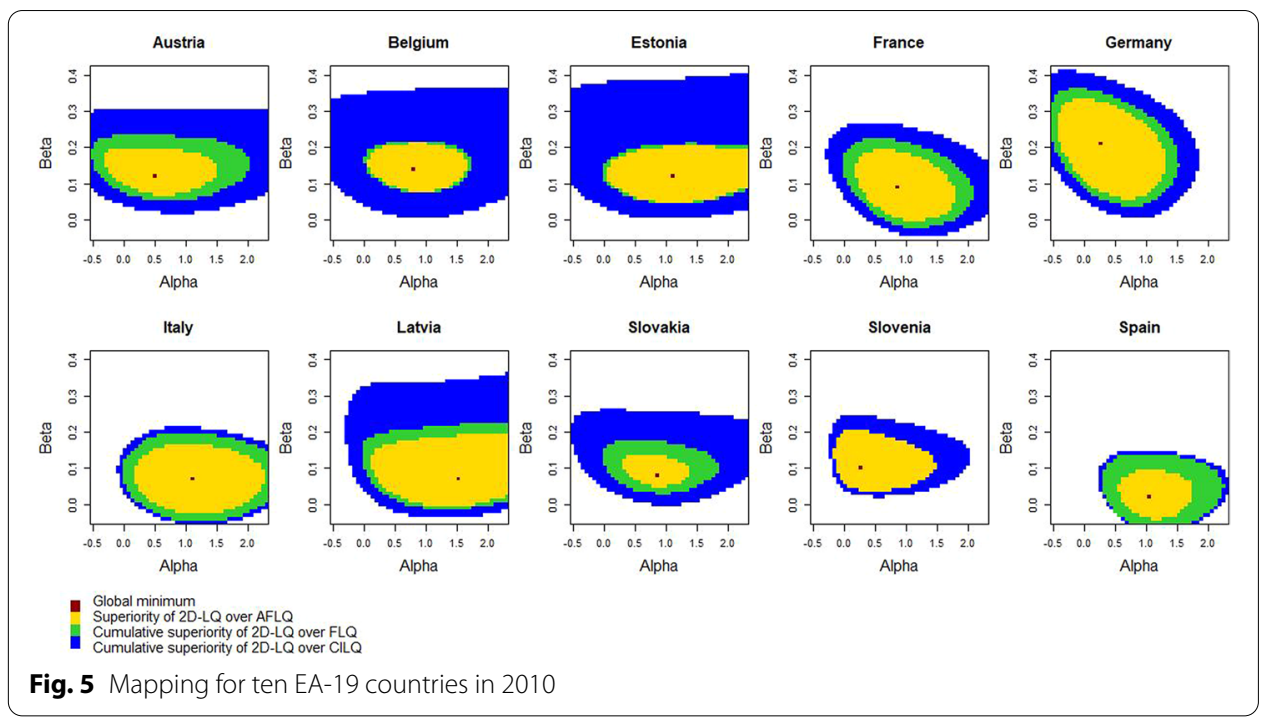

and 1.28 and 0.08 and 0.21 . In light of the obtained STPEs ( $z$ axis), the behaviors of France, Germany, Italy, and Spain are better than the rest, most likely because of their size in the EA-19. Moreover, it is understood that generating IO tables for sub-territories with a reduced proportion within the total could be misleading, particularly if no postadjustment techniques are implemented.

\section{Discussion and conclusions}

We compare the four studied LQs in this section, which entails extracting combined information, initially from Figs. 1 and 3, and then from Figs. 2 and 4. Scalar field intercessions are essentially based on the traditional LQs for the different countries and the 2 years studied, yielding areas delimited by contour lines conditioned by CILQ, FLQ, and AFLQ values. The validity of the techniques (ordered from lowest to highest) has thus far appeared as follows: CILQ, FLQ, AFLQ, and 2D-LQ. However, FLQ and AFLQ switch in some cases for a slight difference in the statistics, namely Slovenia (2010 and 2015) and Estonia (2015), as indicated above.

We opted to map the different countries (2010 and 2015) to condense results. Figures 5 and 6 focus on rendering an effectively staggered 2D-LQ compared to the other techniques: CILQ, FLQ, and AFLQ. The figures are clearly interpretable. The central core expresses the superiority of 2D-LQ over the next most efficient technique, which is almost always AFLQ. An intermediate ring appears to mark the distance between AFLQ and FLQ (though this ring clearly does not exist in the three noted exceptions). Finally, an outer ring reflects the superiority of FLQ over CILQ. The shapes of the areas have some homogeneity, and the global minima given by optimal pairs (2D-LQ) are more or less centered. Numerous parameter combinations yield better statistics compared to other techniques, which merely requires looking at the epicenters and recalling the convexity of the scalar fields in Figs. 3 and 4. Concerning the degree of rigidity of parameters $\alpha$ and $\beta, \beta$ is clearly more sensitive; i.e., small changes lead to bigger errors. In effect, the ratio used between $\alpha$ and $\beta$ to design the charts is $4 / 1$. 

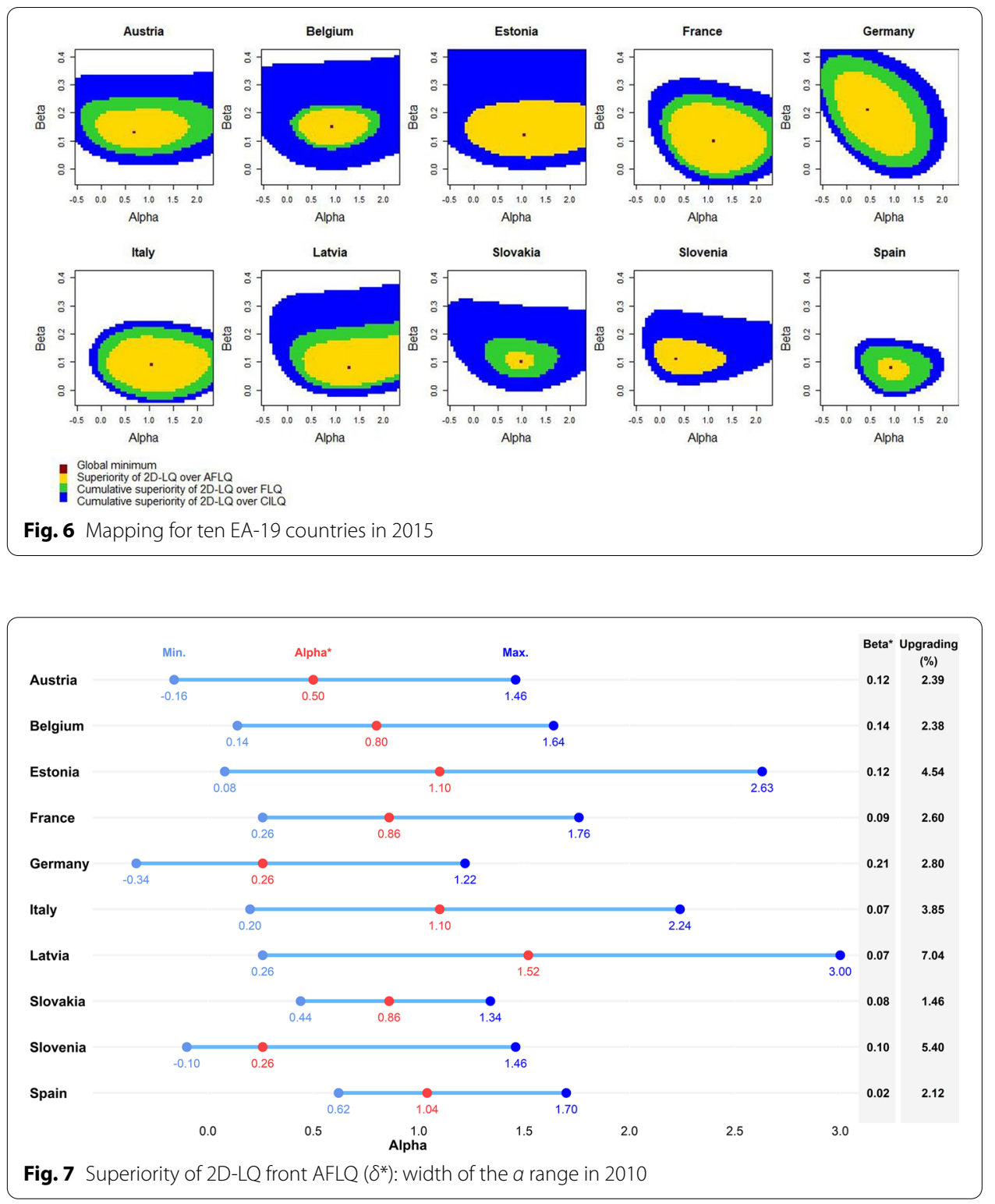

These figures exclude the STPE values, though it is evident that the lower they are, the more difficult it is to reduce them. For comparison, the largest country, Germany (year 2010), reduces the STPE from 56.54 (CILQ) to 53.38 (2D-LQ), so the improvement in stages from CILQ is $1.88 \%$ (FLQ), $2.86 \%$ (AFLQ), and $5.58 \%$ (2D-LQ). This gradual reduction is shown in the corresponding chart. In relation to another much smaller country, Slovakia (2010), its STPE went from 80.19 (CILQ) to 72.32 (2D-LQ). The improvements are 6.16\% (FLQ), 8.48\% (AFLQ), and 9.82\% (2D-LQ), as shown in the illustration.

Only concerning AFLQ, Figs. 7 and 8 reveal the range of $\alpha$ values (associated with the optimal $\beta$ value) for 2010 and 2015, respectively. Optimal $\beta$ values and less errors in 2D-LQ vs. AFLQ. The intervals express a considerable amplitude, i.e., parameters linked to row rectifications do not excessively incur estimated penalties, which is 


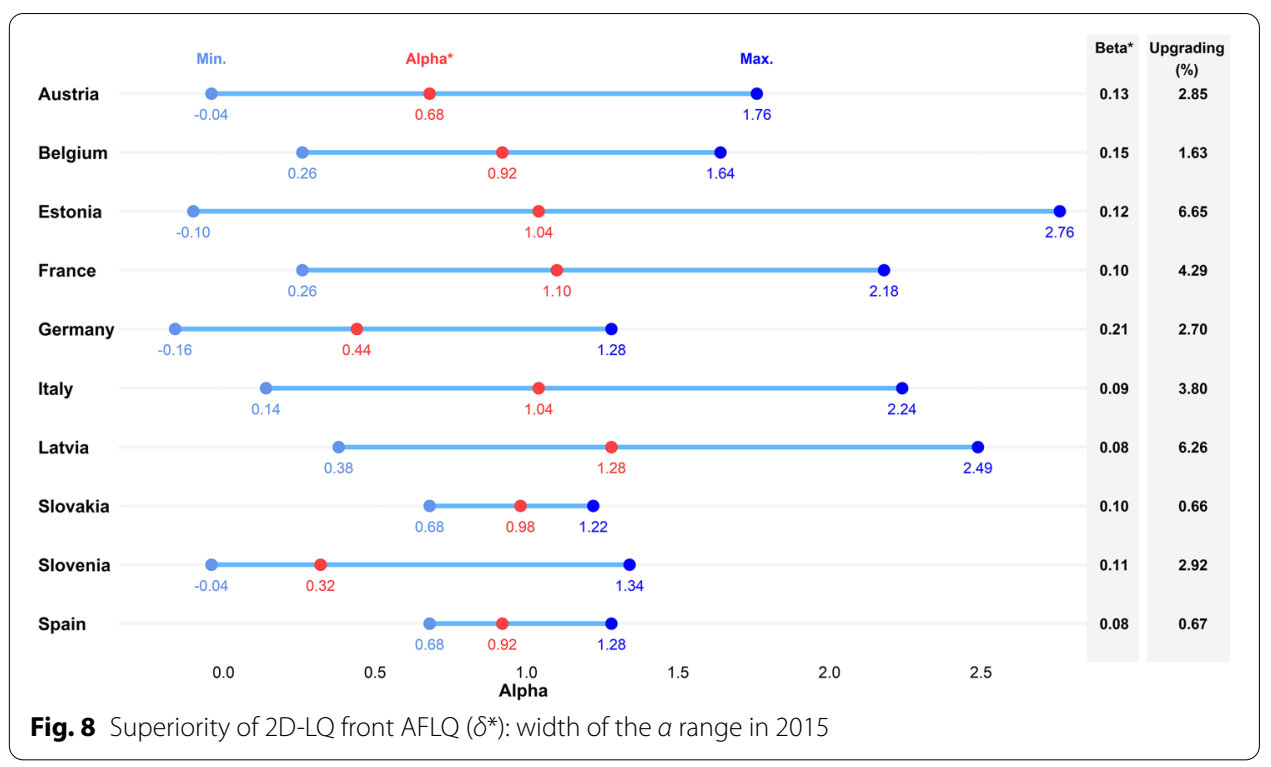

significant since an average value can be set regardless of the sub-territory size. This thus ensures errors lower than the AFLQ. The width of $\beta$ intervals is much smaller than $\alpha$ intervals. In principle, it is possible to work with an average value of $\beta$ around 0.10 , except Germany (larger country). By way of synthesis, it should be noted that the comparison between AFLQ and 2D-LQ techniques affords us a guide to parameters that can be used in this field of work.

There is no clear relationship between the width of 2D-LQ method parameter ranges and its relative distance with the AFLQ method. Of course, for all the subterritories studied, the 2D-LQ method has a wide range of parameters that guarantee fewer errors than the AFLQ in the optimal $\delta$ (generally unknown).

In conclusion, this study contrasted matrices element by element, but not by vector sums for rows or columns. This working method is deemed appropriate to forestall possible compensation for errors. The results of the statistics are consistent with those of other similar studies. The 2D-LQ method demonstrably improves the estimates of prior LQs (CILQ, FLQ and AFLQ). Therefore, this technique is useful, yet requires a longer journey, at least for the sake of parameter contrasting. It is nevertheless recommended to supplement IO tables (via 2D-LQ or another LQ) with optimization processes, so long as there is additional information, e.g., other macroeconomic magnitudes not used in the LQ equations. In this regard, resorting to basic RAS or cross-entropy (Lamonica et al. 2020) could be somewhat misleading since LQs are applied in contexts that lack information. Adjustments are thus suggested for projections secured through the Euromethod or Path-RAS (Mahajan et al. 2018). Both techniques are, in a way, generalizations of the basic RAS and characterized by implementing other types of adjustments in light of the lack of available information. This was in any case not the purpose of this article yet should nevertheless be the object of a future and necessary research.

\section{Appendix}

See Table 1. 
Table 1 Assessment of $\mathrm{IO}$ table projections via LQs for EA-19 countries (2010 and 2015)

\begin{tabular}{|c|c|c|c|c|c|c|c|c|}
\hline \multirow[t]{2}{*}{ Countries } & \multicolumn{4}{|l|}{2010} & \multicolumn{4}{|l|}{2015} \\
\hline & Q & $\operatorname{FLQ}(\delta)$ & $\operatorname{AFLQ}(\delta)$ & $\begin{array}{l}2 \mathrm{D}-\mathrm{LQ} \\
(\alpha ; \beta)\end{array}$ & CILQ & $\operatorname{FLQ}(\delta)$ & $\operatorname{AFLQ}(\delta)$ & $\begin{array}{l}2 \mathrm{D}-\mathrm{LQ} \\
(\alpha ; \beta)\end{array}$ \\
\hline \multicolumn{9}{|l|}{ STPE } \\
\hline ustria & 995 & $\begin{array}{l}69.6879 \\
(0.18)\end{array}$ & $\begin{array}{l}68.2299 \\
(0.20)\end{array}$ & \multicolumn{2}{|c|}{$\begin{array}{l}66.6016(0.50 ; 75.4435 \\
0.12)\end{array}$} & $\begin{array}{l}70.9785 \\
(0.19)\end{array}$ & $\begin{array}{l}69.0646 \\
(0.21)\end{array}$ & $\begin{array}{l}67.0937(0.68 ; \\
0.13)\end{array}$ \\
\hline gium & 4562 & $\begin{array}{l}68.6528 \\
(0.21)\end{array}$ & $\begin{array}{l}68.3947 \\
(0.24)\end{array}$ & \multicolumn{2}{|c|}{$\begin{array}{l}66.7671(0.80 ; 77.0734 \\
0.14)\end{array}$} & $\begin{array}{l}69.3534 \\
(0.25)\end{array}$ & $\begin{array}{l}68.7097 \\
(0.26)\end{array}$ & $\begin{array}{l}67.5910(0.92 ; \\
0.15)\end{array}$ \\
\hline tonia & 9 & $\begin{array}{l}81.6705 \\
(0.13)\end{array}$ & $\begin{array}{l}81.1942 \\
(0.17)\end{array}$ & \multicolumn{2}{|c|}{$\begin{array}{l}77.5070(1.10 ; 94.3536 \\
0.12)\end{array}$} & $\begin{array}{l}82.6840 \\
(0.12)\end{array}$ & & $\begin{array}{l}77.1978(1.04 ; \\
0.12)\end{array}$ \\
\hline ance & 5088 & $\begin{array}{l}50.1284 \\
(0.17)\end{array}$ & $\begin{array}{l}49.3062 \\
(0.20)\end{array}$ & \multicolumn{2}{|c|}{$\begin{array}{l}48.0252(0.86 ; 55.0476 \\
0.09)\end{array}$} & $\begin{array}{l}53.1773 \\
(0.19)\end{array}$ & $\begin{array}{l}52.2111 \\
(0.20)\end{array}$ & $\begin{array}{l}49.9730(1.10 ; \\
0.10)\end{array}$ \\
\hline erm & 91 & $\begin{array}{l}55.4739 \\
(0.18)\end{array}$ & $\begin{array}{l}54.9237 \\
(0.31)\end{array}$ & \multicolumn{2}{|c|}{$\begin{array}{l}53.3835(0.26 ; 58.0644 \\
0.21)\end{array}$} & $\begin{array}{l}56.8606 \\
(0.20)\end{array}$ & $\begin{array}{l}55.7934 \\
(0.32)\end{array}$ & $872(0.44$ \\
\hline aly & 537 & $\begin{array}{l}52.0088 \\
(0.08)\end{array}$ & $\begin{array}{l}50.9841 \\
(0.13)\end{array}$ & \multicolumn{2}{|c|}{$\begin{array}{l}49.0212(1.10 ; 55.2133 \\
0.07)\end{array}$} & $\begin{array}{l}54.2537 \\
(0.12)\end{array}$ & $\begin{array}{l}53.0440 \\
(0.15)\end{array}$ & $\begin{array}{l}51.0279(1.04 ; \\
0.09)\end{array}$ \\
\hline Latvia & 84 & $\begin{array}{l}83.7678 \\
(0.15)\end{array}$ & $\begin{array}{l}81.7131 \\
(0.17)\end{array}$ & \multicolumn{2}{|c|}{$\begin{array}{l}75.9635(1.52 ; 90.7480 \\
0.07)\end{array}$} & $\begin{array}{l}82.8537 \\
(0.17)\end{array}$ & $\begin{array}{r}79 \\
(0.1\end{array}$ & 90 (1.28; \\
\hline ava & 889 & $\begin{array}{l}75.2500 \\
(0.15)\end{array}$ & $\begin{array}{l}73.3860 \\
(0.18)\end{array}$ & \multicolumn{2}{|c|}{$\begin{array}{l}72.3167(0.86 ; 83.9898 \\
0.08)\end{array}$} & $\begin{array}{l}77.8713 \\
(0.19)\end{array}$ & & \\
\hline lovenia & 660 & $\begin{array}{r}78.6 \\
(0.09\end{array}$ & $\begin{array}{l}79.4358 \\
(0.14)\end{array}$ & \multicolumn{2}{|c|}{$\begin{array}{l}75.1431(0.26 ; 84.6056 \\
0.10)\end{array}$} & $\begin{array}{l}78.7981 \\
(0.12)\end{array}$ & & 08 (0.32; \\
\hline ain & 42 & $\begin{array}{r}56 \\
(0.0\end{array}$ & $\begin{array}{l}54.8686 \\
(0.09)\end{array}$ & \multicolumn{2}{|c|}{$\begin{array}{l}53.7071(1.04 ; 61.0079 \\
0.02)\end{array}$} & $\begin{array}{l}60 . \\
(0.10\end{array}$ & 538 & $\begin{array}{l}58.4667(0.92 ; \\
0.08)\end{array}$ \\
\hline \multicolumn{9}{|l|}{$M A D$} \\
\hline ctri & 44 & (0.18) & $0(0.20)$ & $\begin{array}{l}0) 0.0040(0.50 \text {; } \\
0.12)\end{array}$ & 0.0043 & $0.0040(0.19)$ & 0.0039 & $\begin{array}{l}0.0038(0.68 \text {; } \\
0.13)\end{array}$ \\
\hline 7 & 46 & 0.00 & $0.0041(0.24)$ & $\begin{array}{l}\text { 4) } 0.0041 \text { (0.80; } \\
0.14)\end{array}$ & 0.0045 & $0.0041(0.25)$ & 0.0040 & $\begin{array}{l}0.0040(0.92 ; \\
0.15)\end{array}$ \\
\hline Estonia & 48 & $0.0042(0.13)$ & $0.0042(0.17)$ & $\begin{array}{l}\text { 7) } 0.0040(1.10 \text {; } \\
0.12)\end{array}$ & 0.0048 & $0.0042(0.12)$ & $0.0042(0.18)$ & $\begin{array}{l}0.0039(1.04 ; \\
0.12)\end{array}$ \\
\hline ance & 033 & $0.0033(0.17)$ & $0.0032(0.20)$ & $\begin{array}{l}0) 0.0031(0.86 \text {; } \\
0.09)\end{array}$ & 0.0034 & $0.0033(0.19)$ & \multicolumn{2}{|c|}{ ) $\begin{array}{c}0.0032(0.20) \\
0.0031(1.10 ; \\
0.10)\end{array}$} \\
\hline erm & 036 & $0.0036(0$ & $0.0035(0.31)$ & $\begin{array}{l}\text { 1) } 0.0034(0.26 \text {; } \\
0.21)\end{array}$ & 0.0036 & $0.0035(0.20)$ & \multicolumn{2}{|c|}{ D) $\begin{array}{c}0.0035(0.32) \\
0.0034(0.44 \text {; } \\
0.21)\end{array}$} \\
\hline ly & 38 & $0.0037(0.08)$ & $0.0037(0.13)$ & $\begin{array}{l}\text { 3) } 0.0035(1.10 \text {; } \\
0.07)\end{array}$ & 0.0040 & $0.0039(0.12)$ & \multicolumn{2}{|c|}{$\begin{array}{c}0.0038(0.15) \\
0.0037(1.04 ; \\
0.09)\end{array}$} \\
\hline atvia & 58 & $0.0053(0.15)$ & $0.0052(0.17)$ & $\begin{array}{l}\text { 7) } 0.0048(1.52 \text {; } \\
0.07)\end{array}$ & 0.0050 & $0.0046(0.17)$ & \multicolumn{2}{|c|}{ 7) $\begin{array}{c}0.0044(0.18) \\
0.0041(1.28 \\
0.08)\end{array}$} \\
\hline Slovakia & 0.0047 & (0.15) & $0.0043(0.18)$ & $\begin{array}{l}0.0043(0.86 \\
0.08)\end{array}$ & 0.0050 & 0.00 & $0.0045(0.20)$ & $\begin{array}{l}0.0045(0.98 \\
0.10)\end{array}$ \\
\hline ovenia & 047 & $0.0045(0.09)$ & $0.0045(0.14)$ & $\begin{array}{l}0.0043(0.26 \\
0.10)\end{array}$ & 0.0047 & $0.0044(0.12)$ & $0.0044(0.14)$ & $\begin{array}{l}0.0043(0.32 \\
0.11)\end{array}$ \\
\hline Spain & 39 & $0.0039(0.06)$ & 0.0038 & $\begin{array}{l}0.0037(1.04 \\
0.02)\end{array}$ & 0.0040 & $0.0040(0.10)$ & 0.0039 & $\begin{array}{l}0.0039(0.92 ; \\
0.08)\end{array}$ \\
\hline & & & & & & & & \\
\hline ustria & 191 & $0.0181(0.18)$ & $0.0177(0.20)$ & $\begin{array}{l}0.0173(0.50 \\
0.12)\end{array}$ & 0.0196 & $0.0185(0.19)$ & 0.0180 & $\begin{array}{l}0.0175(0.68 \\
0.13)\end{array}$ \\
\hline Belgium & 196 & $0.0179(0.21)$ & $0.0178(0.24)$ & $\begin{array}{l}0.0174(0.80 \\
0.14)\end{array}$ & 0.0201 & $0.0180(0.25)$ & $0.0179(0.26)$ & $\begin{array}{l}0.0176(0.92 ; \\
0.15)\end{array}$ \\
\hline stomid & 0.0240 & $0.0212(0.13)$ & $0.0211(0.17)$ & $\begin{array}{l}0.0202(1.10 \\
0.12)\end{array}$ & 0.0245 & $0.0215(0.12)$ & 0.0215 & $\begin{array}{l}0.0201(1.04 \\
0.12)\end{array}$ \\
\hline ance & 34 & $0.0130(0.17)$ & $0.0128(0.20)$ & $\begin{array}{l}0.0125(0.86 \\
0.09)\end{array}$ & 0.0143 & $0.0138(0.19)$ & $0.0136(0.20)$ & $\begin{array}{l}0.0130(1.10 \text {; } \\
0.10)\end{array}$ \\
\hline ermany & 0.0147 & $0.0144(0.18)$ & $0.0143(0.31)$ & $\begin{array}{l}0.0139(0.26 \\
0.21)\end{array}$ & 0.0151 & $0.0148(0.20)$ & 0.0145 & $\begin{array}{l}0.0141(0.44 ; \\
0.21)\end{array}$ \\
\hline
\end{tabular}


Table 1 (continued)

\begin{tabular}{|c|c|c|c|c|c|c|c|c|}
\hline \multirow[t]{2}{*}{ Countries } & \multicolumn{4}{|l|}{2010} & \multicolumn{4}{|l|}{2015} \\
\hline & CILQ & $\operatorname{FLQ}(\delta)$ & $\operatorname{AFLQ}(\delta)$ & $\begin{array}{l}2 \mathrm{D}-\mathrm{LQ} \\
(\alpha ; \beta)\end{array}$ & CILQ & $\operatorname{FLQ}(\delta)$ & $\operatorname{AFLQ}(\delta)$ & $\begin{array}{l}2 \mathrm{D}-\mathrm{LQ} \\
(\alpha ; \beta)\end{array}$ \\
\hline aly & 7 & .08) & 0. & $\begin{array}{l}0.0128(1.10 \text {; } \\
0.07)\end{array}$ & 0.0144 & .12) & .15) & $\begin{array}{l}\text { 5) } 0.0133(1.04 \text {; } \\
0.09)\end{array}$ \\
\hline atvia & 237 & $0.0218(0.15)$ & $0.0213(0.17)$ & $\begin{array}{l}0.0198(1.52 \text {; } \\
0.07)\end{array}$ & 0.0236 & $0.0216(0.17)$ & ) $0.0207(0.18)$ & $\begin{array}{l}\text { 3) } 0.0194(1.28 \text {; } \\
0.08)\end{array}$ \\
\hline lovakia & 209 & $0.0196(0.15)$ & ) $0.0191(0.18)$ & $\begin{array}{l}0.0188(0.86 \\
0.08)\end{array}$ & 0.0218 & $0.0203(0.19)$ & ) $0.0198(0.20)$ & $\begin{array}{l}0.0197(0.98 ; \\
0.10)\end{array}$ \\
\hline ב & 214 & $0.0205(0.09)$ & $0.0207(0.14)$ & $\begin{array}{l}0.0195(0.26 \text {; } \\
0.10)\end{array}$ & 0.0220 & $0.0205(0.12)$ & $0.0205(0.14)$ & $\begin{array}{l}\text { t) } 0.0199(0.32 \text {; } \\
0.11)\end{array}$ \\
\hline pain & 147 & $0.0147(0.06)$ & $0.0143(0.09)$ & $\begin{array}{l}0.0140(1.04 ; \\
0.02)\end{array}$ & 0.0159 & $0.0156(0.10)$ & ) $0.0153(0.13)$ & $\begin{array}{l}0.0152(0.92 \text {; } \\
0.08)\end{array}$ \\
\hline \multicolumn{9}{|l|}{$S D-M A D$} \\
\hline ustria & 137 & 0.0137 & $0.0134(0.05)$ & $\begin{array}{l}0.0135(0.56 \text {; } \\
0.01)\end{array}$ & 0.0135 & $0.0135(0.01)$ & $0.0130(0.06)$ & $\begin{array}{l}\text { 5) } 0.0130(0.74 \text {; } \\
0.01)\end{array}$ \\
\hline elgium & 0151 & $0.0144(0.12)$ & $0.0144(0.15)$ & $\begin{array}{l}0.0143(0.56 \text {; } \\
0.06)\end{array}$ & 0.0153 & $0.0141(0.15)$ & $0.0140(0.18)$ & $\begin{array}{l}\text { 3) } 0.0141(0.80 \text {; } \\
0.07)\end{array}$ \\
\hline tonia & 0.0150 & $0.0132(0.09)$ & $0.0134(0.15)$ & $\begin{array}{l}0.0129(0.80 \text {; } \\
0.05)\end{array}$ & 0.0151 & $0.0129(0.10)$ & $0.0132(0.16)$ & $\begin{array}{l}0.0126(0.62 \text {; } \\
0.07)\end{array}$ \\
\hline an & 086 & $0.0084(0.09)$ & $0.0081(0.13)$ & $\begin{array}{l}0.0075(0.92 \text {; } \\
0.03)\end{array}$ & 0.0092 & $0.0087(0.15)$ & $0.0082(0.19)$ & $\begin{array}{l}0.0074(0.92 \text {; } \\
0.05)\end{array}$ \\
\hline 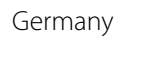 & 2 & $0.0102(0.00)$ & $0.0101(0.09)$ & $\begin{array}{l}0.0097(0.62 \\
0.00)\end{array}$ & 0.0101 & $0.0101(0.00)$ & $0.097(0.11)$ & $\begin{array}{l}\text { ) } 0.0092(0.80 \text {; } \\
0.01)\end{array}$ \\
\hline Italy & 0.0108 & $0.0100(0.19)$ & $0.0097(0.24)$ & $\begin{array}{l}0.0094(0.98 \\
0.09)\end{array}$ & 0.0112 & $0.0102(0.19)$ & $0.0100(0.23)$ & $\begin{array}{l}\text { 3) } 0.0093(1.16 \text {; } \\
0.11)\end{array}$ \\
\hline atvia & 68 & $0.0161(0.06)$ & $0.0156(0.13)$ & $\begin{array}{l}0.0145(1.10 \text {; } \\
0.03)\end{array}$ & 0.0167 & $0.0166(0.02)$ & $0.0159(0.10)$ & $\begin{array}{l}0.0148 \text { (0.92; } \\
0.01)\end{array}$ \\
\hline Iry & 0.0140 & $0.0139(0.02)$ & $0.0137(0.10)$ & $\begin{array}{l}0.0136(0.44 \text {; } \\
0.02)\end{array}$ & ; 0.0155 & $0.0154(0.03)$ & $0.0150(0.10)$ & $\begin{array}{l}0.0151(0.50 \text {; } \\
0.02)\end{array}$ \\
\hline (1) & 145 & $0.0140(0.05)$ & $0.0145(0.10)$ & $\begin{array}{l}0.0141(0.08 \text {; } \\
0.06)\end{array}$ & 0.0162 & $0.0156(0.06)$ & $0.0157(0.11)$ & $\begin{array}{l}0.0154(0.14 \text {; } \\
0.06)\end{array}$ \\
\hline Spain & 0 & $0.0109(0.06)$ & $0.0105(0.11)$ & $\begin{array}{l}0.0104(0.92 ; \\
0.00)\end{array}$ & 0.0125 & $0.0123(0.08)$ & $0.0120(0.13)$ & $\begin{array}{l}\text { 3) } 0.0122 \text { (0.56; } \\
0.03)\end{array}$ \\
\hline \multicolumn{9}{|l|}{ Theils } \\
\hline Ustria & 455 & $\begin{array}{l}61.1455 \\
(0.00)\end{array}$ & $\begin{array}{l}59.6314 \\
(0.06)\end{array}$ & $\begin{array}{l}60.4973 \\
(0.56 ; 0.02)\end{array}$ & 61.4834 & $\begin{array}{l}61.4269 \\
(0.01)\end{array}$ & $\begin{array}{l}59.0615 \\
(0.07)\end{array}$ & $\begin{array}{l}08 \\
0.02)\end{array}$ \\
\hline 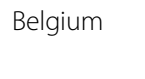 & 3667 & $\begin{array}{l}68.5536 \\
(0.13)\end{array}$ & $\begin{array}{l}68.6360 \\
(0.15)\end{array}$ & $\begin{array}{l}68.2197(0.62 ; \\
0.07)\end{array}$ & & $\begin{array}{l}68.7492 \\
(0.16)\end{array}$ & $\begin{array}{l}68.4625 \\
(0.19)\end{array}$ & $\begin{array}{r}68.5 \\
(0.80\end{array}$ \\
\hline Estonia & 8 & $\begin{array}{l}72.5117 \\
(0.09)\end{array}$ & $\begin{array}{l}73.7562 \\
(0.15)\end{array}$ & $\begin{array}{l}70.8120(0.86 ; \\
0.06)\end{array}$ & & $\begin{array}{l}74.7504 \\
(0.10)\end{array}$ & $\begin{array}{l}76.3152 \\
(0.16)\end{array}$ & $\begin{array}{l}73.0488(0.62 ; \\
0.07)\end{array}$ \\
\hline ance & 0037 & $\begin{array}{l}45.8011 \\
(0.09)\end{array}$ & $\begin{array}{l}44.0643 \\
(0.13)\end{array}$ & $\begin{array}{l}41.0625(0.92 ; \\
0.03)\end{array}$ & & $\begin{array}{l}48.7922 \\
(0.16)\end{array}$ & $\begin{array}{l}46.6069 \\
(0.19)\end{array}$ & $\begin{array}{l}42.2002(0.98 \\
0.05)\end{array}$ \\
\hline entrany & 6259 & $\begin{array}{l}49.6259 \\
(0.00)\end{array}$ & $\begin{array}{l}49.3755 \\
(0.10)\end{array}$ & $\begin{array}{l}47.5895(0.62 ; \\
0.01)\end{array}$ & $; 50.3366$ & $\begin{array}{l}50.3366 \\
(0.00)\end{array}$ & $\begin{array}{l}48.8274 \\
(0.12)\end{array}$ & $\begin{array}{l}46.5817(0.80 \\
0.02)\end{array}$ \\
\hline Italy & 2963 & $\begin{array}{l}54.3184 \\
(0.18)\end{array}$ & $\begin{array}{l}53.0215 \\
(0.23)\end{array}$ & $\begin{array}{l}50.9990(0.98 ; \\
0.09)\end{array}$ & ;61.7249 & $\begin{array}{l}57.1349 \\
(0.18)\end{array}$ & $\begin{array}{l}55.6855 \\
(0.23)\end{array}$ & $\begin{array}{l}52.1613(1.16 \\
0.11)\end{array}$ \\
\hline Latvia & 78.4507 & $\begin{array}{l}74.9980 \\
(0.07)\end{array}$ & $\begin{array}{l}72.7200 \\
(0.13)\end{array}$ & $\begin{array}{l}67.3222(1.10 ; \\
0.03)\end{array}$ & $; 72.9161$ & $\begin{array}{l}72.2389 \\
(0.03)\end{array}$ & $\begin{array}{l}69.0737 \\
(0.10)\end{array}$ & $\begin{array}{l}64.4627(0.92 ; \\
0.01)\end{array}$ \\
\hline IOVakia & 65.9687 & $\begin{array}{l}65.4229 \\
(0.03)\end{array}$ & $\begin{array}{l}64.3763 \\
(0.10)\end{array}$ & $\begin{array}{l}64.2581(0.44 ; \\
0.03)\end{array}$ & $; 69.3574$ & $\begin{array}{l}68.5305 \\
(0.04)\end{array}$ & $\begin{array}{l}66.8900 \\
(0.11)\end{array}$ & $\begin{array}{l}67.3646 \\
(0.56 ; 0.02)\end{array}$ \\
\hline lovenia & 74.6075 & $\begin{array}{l}71.8624 \\
(0.05)\end{array}$ & $\begin{array}{l}74.3736 \\
(0.10)\end{array}$ & $\begin{array}{l}72.1310 \\
(0.14 ; 0.06)\end{array}$ & 79.5425 & $\begin{array}{l}76.4087 \\
(0.07)\end{array}$ & $\begin{array}{l}77.0159 \\
(0.12)\end{array}$ & $\begin{array}{l}75.8484(0.20 \\
0.06)\end{array}$ \\
\hline Spain & 52.9878 & $\begin{array}{l}52.2704 \\
(0.06)\end{array}$ & $\begin{array}{l}50.4862 \\
(0.11)\end{array}$ & $\begin{array}{l}49.8286(0.92 ; \\
0.00)\end{array}$ & 58.4636 & $\begin{array}{l}57.3348 \\
(0.08)\end{array}$ & $\begin{array}{l}55.9103 \\
(0.13)\end{array}$ & $\begin{array}{l}56.9373 \\
(0.62 ; 0.03)\end{array}$ \\
\hline
\end{tabular}

The optimal parameter values for each LQs are indicated in parentheses. The global minimum for the statistic is shown in italic 


\section{Supplementary Information}

The online version contains supplementary material available at https://doi.org/10.1186/s40008-021-00237-5.

Additional file 1. Projection via LQs for Austria in 2010.

\section{Acknowledgements}

The authors would like to thank the editor and the three referees for their comments and suggestions, which have improved this article.

\section{Authors' contributions}

All authors have made substantial contributions. All authors read and approved the final manuscript.

\section{Funding}

Not applicable.

Availability of data and materials

The datasets used and analyzed during the current study are available from the corresponding author on request.

\section{Declarations}

Ethics approval and consent to participate

Not applicable.

\section{Consent for publication}

Not applicable.

\section{Competing interests}

The authors declare that they have no competing interests.

\section{Author details}

Institute of Development Studies of Galicia (IDEGA), University of Santiago de Compostela, Avda. das Ciencias, Chalet no 1, Campus Universitario Sur, 15782 Santiago de Compostela, Spain. ${ }^{2}$ Department of Quantitative Economics, University of Santiago de Compostela, Avda. do Burgo das Nacións, s/n, 15782 Santiago de Compostela, Spain. ${ }^{3}$ Departamento de Estudios Organizacionales y Desarrollo Humano, Escuela Politécnica Nacional, Avda. Ladrón de Guevara, E11-253, P.O. Box 17-01-2759, Quito, Ecuador. ${ }^{4}$ Department of Fundamentals of Economic Analysis, University of Santiago de Compostela, Avda. do Burgo das Nacións, s/n, 15782 Santiago de Compostela, Spain.

Received: 17 August 2020 Revised: 26 April 2021 Accepted: 2 June 2021

Published online: 11 June 2021

\section{References}

Bonfiglio A (2005) Can nonsurvey methods substitute for survey-based models? A performance analysis of indirect techniques of estimating IO coefficients and multipliers. In: Quaderno di ricerca number 230. Ancona: Dipartimento di Scienze Economiche e Sociali, Universita' Politecnica delle Marche

Bonfiglio A (2009) On the parameterization of techniques for representing regional economic structures. Econ Syst Res 21:115-127

Bonfiglio A, Chelli F (2008) Assessing the behaviour of nonsurvey methods for constructing regional input-output tables through a Monte Carlo simulation. Econ Syst Res 20:243-258

Flegg AT, Tohmo T (2013) Regional input-output tables and the FLQ formula: a case study of Finland. Reg Stud 47:703-721

Flegg AT, Tohmo T (2016) Estimating regional input coefficients and multipliers: the use of FLQ is not a gamble. Reg Stud 50:310-325

Flegg AT, Tohmo T (2019) The regionalization of national input-output tables: a study of South Korean regions. Pap Reg Sci 98:601-620

Flegg AT, Webber CD (1997) On the appropriate use of location quotients in generating regional input-output tables: reply. Reg Stud 31:795-805

Flegg AT, Webber CD (2000) Regional size, regional specialization and the FLQ formula. Reg Stud 34:563-569

Flegg AT, Webber CD, Elliott MV (1995) On the appropriate use of location quotients in generating regional inputoutput tables. Reg Stud 29:547-561

Flegg AT, Mastronardi LJ, Romero CA (2016) Evaluating the FLQ and AFLQ formulae for estimating regional input coefficients: empirical evidence for the province of Córdoba, Argentina. Econ Syst Res 28:21-37

Jackson RW, Murray AT (2004) Alternative input-output matrix updating formulations. Econ Syst Res 16:135-148 Jahn M, Flegg AT, Tohmo T (2020) Testing and implementing a new approach to estimating interregional output multipliers using input-output data for South Korean regions. Spat Econ Anal 00:1-21 
Jalili AR (2000) Comparison of two methods of identifying input-output coefficients for exogenous estimation. Econ Syst Res 12:113-129

Kowalewksi I (2015) Regionalization of national input-output tables: empirical evidence on the use of the FLQ formula. Reg Stud 49:240-250

Lahr ML, Stevens BH (2002) A study of the role of regionalization in the generation of aggregation error in regional inputoutput models. J Reg Sci 42:477-507

Lamonica GR, Chelli FM (2018) The performance of nonsurvey techniques for constructing sub-territorial input-output tables. Pap Reg Sci 97:1169-1202

Lamonica GR, Recchioni MC, Chelli FM, Salvati L (2020) The efficiency of the cross-entropy method when estimating the technical coefficients of input-output tables. Spat Econ Anal 15:62-91

Lampiris G, Karelakis C, Loizou E (2019) Comparison of nonsurvey techniques for constructing regional input-output tables. Ann Oper Res 294(1):225-266

Mahajan S, Beutel J, Guerrero S, Inomata S, Larsen S, Moyer B, Remond-Tiedrez I, Rueda-Cantuche JM, Simpson LH, Thage B, Van Rompaey C (2018) Handbook on supply, use and input-output tables with extensions and applications. United Nations Publications

McCann P, Dewhurst JHL (1998) Regional size, industrial location and input-output expenditure coefficients. Reg Stud 32:435-444

Miller RE, Blair PD (2009) Input-output analysis: foundations and extensions, 2nd edn. Cambridge University Press, Cambridge

Mínguez R, Oosterhaven J, Escobedo F (2009) Cell-corrected RAS method (CRAS) for updating or regionalizing an inputoutput matrix. J Reg Sci 49:329-348

Morrison WI, Smith P (1974) Nonsurvey input-output techniques at the small area level: an evaluation. J Reg Sci 14:1-14

Oosterhaven J, van der Knijff EC, Eding GJ (2003) Estimating interregional economic impacts: an evaluation of nonsurvey, semisurvey, and full-survey methods. Environ Plan A Econ Sp 35:5-18

Pereira-López X, Carrascal-Incera A, Fernández-Fernández M (2020) A bidimensional reformulation of location quotients for generating input-output tables. Spat Econ Anal 15:1-18

Round JI (1978) An inter-regional input-output approach to the evaluation of nonsurvey methods. J Reg Sci 18:179-194

Schaffer WA, Chu K (1969) Nonsurvey techniques for constructing regional interindustry models. Pap Reg Sci Assoc 23:83-101

Wiebe KS, Lenzen M (2016) To RAS or not to RAS? What is the difference in outcomes in multi-regional input-output models? Econ Syst Res 28:383-402

Zhao X, Choi SG (2015) On the regionalization of input-output tables with an industry-specific location quotient. Ann Reg Sci 54:901-926

\section{Publisher's Note}

Springer Nature remains neutral with regard to jurisdictional claims in published maps and institutional affiliations.

\section{Submit your manuscript to a SpringerOpen ${ }^{\circ}$ journal and benefit from:}

- Convenient online submission

- Rigorous peer review

- Open access: articles freely available online

- High visibility within the field

Retaining the copyright to your article

Submit your next manuscript at $\gg$ springeropen.com 